\title{
Response to inquiry by Gaylinn et al. on 'Administration of UAG improves glycemic control in obese subjects with diabetes'
}

\author{
Behiye Özcan, Sebastian J C M M Neggers, Anne Reifel Miller', Hsiu-Chiung Yang', \\ Virginia Lucaites ${ }^{1}$, Thierry Abribat ${ }^{2}$, Soraya Allas ${ }^{2}$, Martin Huisman, Jenny A Visser, \\ Axel P N Themmen, Eric J G Sijbrands, Patric J D Delhanty and Aart Jan van der Lely \\ Department of Medicine, Erasmus University MC, 3000 CA, Rotterdam, The Netherlands, 'Lilly Research \\ Laboratories, Eli Lilly and Company, Lilly Corporate Center, Indianapolis, Indiana 46285, USA and ${ }^{2}$ Alizé Pharma, \\ 69130 Ecully, France
}

\author{
Correspondence \\ should be addressed \\ to $\mathrm{H}-\mathrm{C}$ Yang \\ Email \\ yang_hsiu-chiung@Lilly.com
}

\section{Dear Editor,}

In a recent Letter to the Editor Gaylinn et al. (1) discuss the outcomes of a study that we published in the European Journal of Endocrinology in which we reported that the administration of unacylated ghrelin (UAG) improves glycemic control in obese subjects with diabetes and (2) that this effect might be mediated by a decrease in acylated ghrelin (AG) levels in response to UAG administration (2). They comment that, while we clearly demonstrated the anti-diabetogenic potential of UAG, our observation that AG levels are suppressed may be an assay artefact. They refer to a similar UAG infusion study by Tong et al. (3) in which a decline in AG was not observed. Gaylinn et al. attribute this to technical differences in the antibody used to capture AG in the sandwich assay. Tong et al. used an assay in which the capture antibody is an N-terminal AG-specific antibody whereas in our study a C-terminal specific antibody was used. Gaylinn et al. argue that when high UAG concentrations are present, as during an infusion study where they can reach $10-20 \mathrm{ng} / \mathrm{ml}$, the UAG may compete for capture at the C-terminal assay antibody and interfere with the detection of AG.

We would like to point out a few critical points which may address the concerns raised by Gaylinn et al.

1. We have assessed the interference in the $A G$ assay under high concentration of UAG (up to $10000 \mathrm{pg} / \mathrm{ml}$ ): in this experiment, we spiked in either 20 or $200 \mathrm{pg} / \mathrm{ml}$ of AG to solutions with various concentration of UAG up to $10000 \mathrm{pg} / \mathrm{ml}$. The recoveries of the AG under these conditions are well within the regulatory clinical biomarker requirements (i.e. 70-130\%) (4). Furthermore, in the UAG infusion experiment, our average peak plasma UAG concentration is $10900 \mathrm{pg} / \mathrm{ml}$. A $20 \%$ lower than expected recovery of $A G$ at the highest concentration of UAG 10000 pg/ml, might be indicative of a small degree of signal suppression under these conditions (Table 1). However, even if taken for face value, this would not explain $>80 \%$ lower level of AG in patients infused with UAG. Consequently, our original finding on the possibility that high concentration of circulating UAG may lead to lower plasma AG remains valid.

2. There are some technical differences that differentiate the assay we used from that used by Tong et al.: in the study by Ozcan et al. (2), we used a new immunoassay technology, by Meso Scale Discovery, Inc. (Rockville, MD, USA), using electro-chemoluminescence (ECL) readout. This immunoassay platform has better sensitivity $(\sim 1 \mathrm{pg} / \mathrm{ml})$ and a wider dynamic range (i.e. five orders of magnitudes). With this wide dynamic range, samples with wide range concentrations of analyte can be loaded to the immunoassays without any dilution. In contrast to our method, the study by Tong et al. used a traditional ELISA with fluorescent detection method, which is known to have narrower dynamic rage than that of the ECL readout.

3. Additionally, the blood samples in those two studies were stabilized in a slightly different way. In the study by Ozcan et al. (2), whole blood was equilibrated in an acidic isotonic solution containing high concentration of AEBSF and NaF, whereas in Tong et al. AEBSF was dissolved in the blood samples and only after preparation of plasma was the sample acidified.

4. Perhaps the most important difference, also pointed out by Gaylinn et al. (1), is that while in the study by

Published by Bioscientifica Ltd. 
Table 1 Fixed concentrations of AG was added to various concentration of UAG, the AG concentration in each sample was measured in the AG assay. All spike recovery experiments were conducted in human plasma.

\begin{tabular}{|c|c|c|c|c|c|c|c|c|}
\hline \multirow[b]{2}{*}{ UAG concentration } & \multicolumn{4}{|c|}{ Spiked $20 \mathrm{pg} / \mathrm{ml}$ AG to indicated concentration of UAG } & \multicolumn{4}{|c|}{ Spiked $200 \mathrm{pg} / \mathrm{ml}$ AG to indicated concentration of UAG } \\
\hline & $\begin{array}{c}\text { Average measured AG } \\
(\mathrm{pg} / \mathrm{ml}) 20 \mathrm{pg} / \mathrm{ml} A G \\
\text { was spiked in }\end{array}$ & S.D. & $\begin{array}{c}\text { Recovery of } \\
\text { spiked } 20 \mathrm{pg} / \mathrm{ml} \\
\text { AG (\%) }\end{array}$ & $\begin{array}{c}\text { S.D. recovery } \\
(\%)\end{array}$ & $\begin{array}{l}\text { Average measured AG } \\
(\mathrm{pg} / \mathrm{ml}) 200 \mathrm{pg} / \mathrm{ml} A G \\
\text { was spiked in }\end{array}$ & S.D. & $\begin{array}{c}\text { Recovery of } \\
\text { spiked } 200 \mathrm{pg} / \mathrm{ml} \\
\text { AG (\%) }\end{array}$ & $\begin{array}{c}\text { S.D. recovery } \\
(\%)\end{array}$ \\
\hline 10000 & 15.8 & 0.3 & 79 & 1 & 163.7 & 0.5 & 82 & 0.3 \\
\hline 5000 & 19.7 & 0.4 & 99 & 2 & 199.6 & 1.1 & 100 & 0.6 \\
\hline 2500 & 21.8 & 0.1 & 109 & 0.3 & 221.8 & 0.6 & 111 & 0.3 \\
\hline 1250 & 23.5 & 0.1 & 117 & 0.3 & 223.8 & 1.4 & 112 & 0.7 \\
\hline 625 & 22.1 & 0.4 & 110 & 2 & 227.7 & 0.5 & 114 & 0.3 \\
\hline 312.5 & 22.7 & 0.2 & 113 & 1 & 240.9 & 4.1 & 120 & 2 \\
\hline 156.3 & 22.7 & 0.2 & 113 & 1 & 232.3 & 1.9 & 116 & 1 \\
\hline 78.1 & 22.7 & 0.1 & 114 & 0.6 & 235.7 & 2.1 & 118 & 1 \\
\hline 39.1 & 22.7 & 0.2 & 113 & 1 & 232.5 & 0.1 & 116 & 0.7 \\
\hline 19.5 & 22.2 & 0.3 & 111 & 2 & 227.8 & 3.8 & 114 & 1.9 \\
\hline
\end{tabular}

Tong et al. (3) healthy volunteers were used, we studied the effects of UAG administration in obese subjects with diabetes (2).

Although we value the concern expressed by Gaylinn et al., the administration of UAG does improve glycemic control in obese diabetes patients. Based on our data, the high concentration of circulating UAG appears to results in lower level of circulating AG. However, we acknowledge that the reduction of circulating AG followed by UAG infusion may not be able to fully explain the therapeutic benefit of UAG. The detailed mechanism(s) of the beneficial effects of UAG on the improvement of glycemic control warrant farther studies. Consequently, we used a cautious title to the study: does des-acyl ghrelin improve glycemic control in obese diabetic subjects by decreasing AG levels? (2).

Declaration of interest

A R Miller, H-C Yang, and V Lucaites are employees of the Eli Lilly Company (Indianapolis, IN, USA); T Abribat and S Allas are employees of Alizé Pharma (Ecully, France); and A J van der Lely is a scientific advisor, shareholder of Alizé Pharma, and guarantor of this work, had full access to all the data, and had full responsibility for the integrity of data and the accuracy of the data analyses.

\section{Funding}

This research did not receive any specific grant from any funding agency in the public, commercial or not-for-profit sector.

\section{References}

1 Gaylinn BD, Farhy LS, Nass R, Tong J \& Thorner MO. Does des-acyl ghrelin improve glycemic control by decreasing acylated ghrelin levels? European Journal of Endocrinology 2015173 L1-L2. (doi:10.1530/EJE-14-1131)

2 Ozcan B, Neggers SJ, Miller AR, Yang HC, Lucaites V, Abribat T, Allas S, Huisman M, Visser JA, Themmen AP et al. Does des-acyl ghrelin improve glycemic control in obese diabetic subjects by decreasing acylated ghrelin levels? European Journal of Endocrinology 2014170 799-807. (doi:10.1530/EJE-13-0347)

3 Tong J, Dave N, Mugundu GM, Davis HW, Gaylinn BD, Thorner MO, Tschop MH, D'Alessio D \& Desai PB. The pharmacokinetics of acyl, des-acyl, and total ghrelin in healthy human subjects. European Journal of Endocrinology 2013168 821-828. (doi:10.1530/EJE-13-0072)

4 Guidance for Industry Bioanalytical Method Validation (page 14), http://www.fda.gov/downloads/drugs/guidancecomplianceregulatoryinformati on/guidances/ucm368107.pdf. 